\title{
Apply Total Quality Management to Innovate the University Management in Vietnam
}

\author{
Nguyen Quang Giao, Ph.D. \\ The University of Danang, Vietnam
}

\begin{abstract}
Total Quality Management (TQM) is a philosophy, a management system widely used in developed countries. TQM derives from the manufacturing sector and is gradually applied on education to ensure and improve the education quality which satisfies increasing requirements of the society. TQM is the highest level of quality management with basic features: Always seeking to satisfy the needs of customers, improving implementation continuously, building quality culture of the organization, ensuring communication and information widely, and changing quality culture through the team work method. Many countries research of applying TQM to education management in general and in management of higher education in particular. The benefits of universities applying TQM in university management are proven that quality of university education has always been ensured and enhanced; at the same time, images and brand of university of high quality education were confirmed in the region and the world. For universities in Vietnam at present, educational quality of universities is always a matter which receives the attention of all members of university, students, parents, the employers and all society. To ensure and improve the quality of education is considered as an important task of all leaders of universities especially the higher education of Vietnam is in process fundamental and comprehensive innovation. Applying TQM to innovate the university management is an important task of higher education system as well as of universities in Vietnam. The article refers to applying TQM to innovate the university management. It is the one of the most comprehensive solutions to ensure and improve education quality of universities as well as actually perform innovating management of universities in Vietnam.
\end{abstract}

Keywords: higher education, process of innovation, quality management, TQM, Vietnam.

\section{Introduction}

TQM is applied first in Japan and thanks to the successful application of TQM and the quality of Japanese products after several decades developed to high and prestigious qualification in the world. After Japan's success of the application of TQM has made many countries do researches on application of TQM to business management and particularly in education management in general and management of higher education in particular. Thanks to applying TQM in management, the education quality of universities are always guaranteed and enhanced, the universities' brand name was created and publicized not only in the region but also worldwide.

In the context of higher education in Vietnam is in process of fundamental and comprehensive innovation, quality of higher education in Vietnam is currently receiving attention not only of universities, teachers, students, and parents of students but also the society. The education quality of higher education becomes pressing issues in which applying TQM in the university management is considered as one of the most comprehensive solutions to help the university ensure and improve education quality.

\section{The Concept of TQM}

TQM is a philosophy, a system, is the highest management level of quality management.

Author Feigenbaum [1] defined: "TQM is an effective system to integrate the efforts of developing, maintaining and improving the quality of the teams, groups within an organization to be able to market, pressure engineering science, manufacturing and service providers to fully satisfy the needs of our customers the most economical way."

TQM is both a philosophy and set of guiding principles that represent the foundation of continuous improving organization. TQM is the application of quantitative method and human resources to improve the materializing services supplied to an organization, all the process in an organization, and the degree to which the needs of the consumer are met, now and in the future [4].

Sims and Sims [3] defined: "TQM is the process of continuous improvement using selected tools, techniques, and training to guide decision making and to plan actions. The results are quality processes, products, and services, and thus high level of customer satisfaction".

Authors Stora Gilbert and Jean Montaigne [2] defines $\mathrm{T}$ in TQM as: sync, comprehensive, integrated, with particular characteristics: Management of all jobs, from small to large; Everyone is a work of quality; Each type of work is set during the life of the design product, production to consumption; Removal to prevent all risks of any plan of organization; The ability to mobilize all material and spiritual to improve the quality continuously; Remove absolutely all defects; Any consumers' needs are met and satisfied.

Voehl [5] provided a diagram of "House of Quality" as shown in the figure below. He describes "The House of Quality" as a well-built house which might collapse if any of its components is weak. 


\section{International Journal of Science and Research (IJSR) \\ ISSN (Online): 2319-7064}

Index Copernicus Value (2013): 6.14 | Impact Factor (2014): 5.611

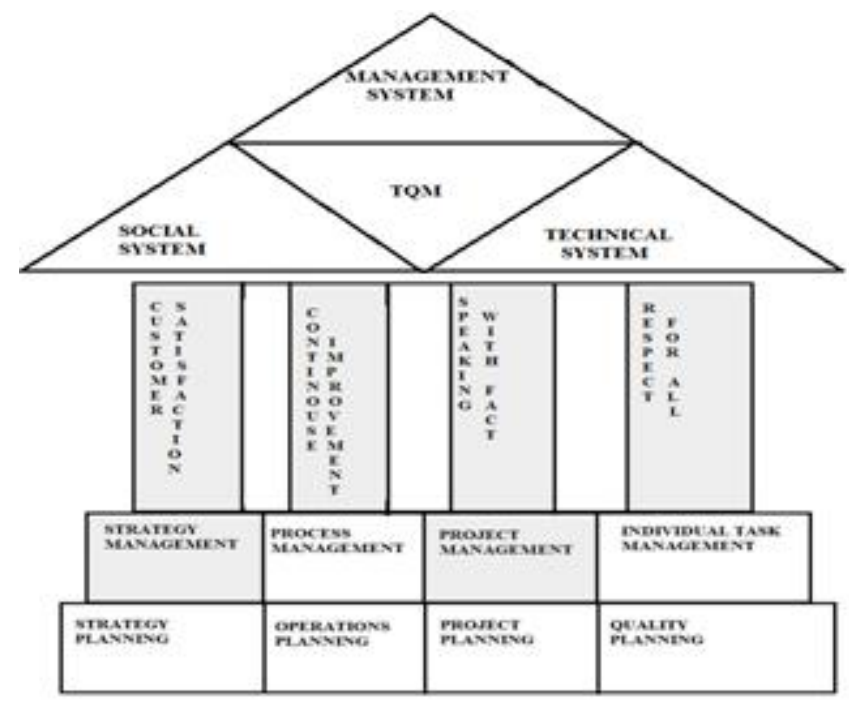

Figure 1: House of Quality (Voehl, 1994)

Although there are many different concepts and different philosophies of many authors, generally people think the TQM is an attention to quality in all activities, is understanding, the commitment and cooperation of all members in the organization, especially at the leadership levels in order to continually improve the provision of services or products towards satisfying customer needs. Moreover, the TQM pays attention to building quality culture of the organization, ensuring communication and information widely; changing culture of quality through work of the group.

\section{The basic characteristics of the TQM}

\section{a) Continuous improvement}

The most important philosophy of TQM is continuous improvement and can be reached by and through the masses. This continuous improvement is reflected in the strategic planning of organizations in the improvement cycles; gradually increased from circular spiral immediate benefits to long-term benefits, from the produce level at a certain time to reach the higher levels.

\section{b) Customer's needs satisfaction}

The customer is the judge of quality. To understand customer needs, both present and future, and to adapt to environmental changes universities should have effective strategies for listening and learning from customers, measuring the customer satisfaction, and building relationships with customers. Customer needs to be closely associated with the university's strategy. Information relating to the satisfaction or dissatisfaction of customers plays an important role because understanding this information can be based for improving satisfaction and meet customer needs.

\section{c) Culture and quality of the organization}

Culture in an organization formed by several elements including: Acts of relations with one another, the standards achieved by working groups, the dominant values held accept participation rules and circumstances. In any other industry, culture can be identified as the dominant faith in the entire organization on how to achieve the business, how employees should behave and be treated.
The concept of quality culture is widely understood as the wide participation of all members of the organization in activities related to quality. Quality culture also includes the processes and tools to develop quality management systems providing various features of the organizations. Processes and tools are only truly meaningful when attached to the core activities of the organization.

\section{d) Communication, information widely}

TQM will significantly change the way organizations operate. This change requires the transfering of information directly and clearly from top management to all officers and staff to explain the need to focus on the process. Each person needs to know its role in understanding the processes and improve their performance.

\section{e) Teamwork}

During operation of the organization there are many complex issues that arise beyond the control of any individual. So use of form of teamwork is the only effective way to implement process improvement as well as problem solving them. Working in teams to solve problems has more advantages than working individually. Teamwork in any organization is also fundamental components of implementing TQM, because it builds confidence, improve information exchange and development of interdependence.

\section{Benefits of applying TQM to University Management}

In the context of deep and strong globalization as today, application and implementation of TQM increasing the competitiveness of institutions of higher education in Vietnam by the potential benefits in implementing TQM is clear.

In present context, the quality of higher education must meet the requirements of the "customer", to satisfy the needs of "clients" and seeks to know "customers' needs" because "consumers" of universities education now are not only merely wished that they were providing what they are provided but also how and the attitudes of those who supply. TQM will help universities provide better services for their first "customers" that are students, parents of students and employers.

One of the basic features of TQM is continuous improvement. Management systems with TQM philosophy of continuous improvement will provide many opportunities and challenges for students than in the learning environment. Thanks to the continuous improvement, learning environment of students can be improved.

In addition, applying TQM in the university management will ensure the active participation of all members of the university as staffs, faculties, students, parents of students, individuals and organizations dealing with university contribution. At the same time, applying TQM will build mechanisms of communication as well as organize meetings with parents and students so that all members can express their views, their concerns and their expectations about the 


\section{International Journal of Science and Research (IJSR) \\ ISSN (Online): 2319-7064}

Index Copernicus Value (2013): 6.14 | Impact Factor (2014): 5.611

university. Through that, the relationship between the university- the family - society becomes more closely and stably.

On the other hand, TQM will create mechanisms to discussion teams, planning and breaking down barriers. Teamwork focusing on improving quality will change the independence of the interdependence through improving communication, trust and free exchange of ideas, knowledge, data materials. Teamwork, at the same time, creates an environment in which people can develop and use all resources efficiently and helpful to create continuous improvement. Through teamwork forms, information, communication will be broad, accurate, and timely. This helps leaders with accuracy decisions to handle necessary cases in the implement process.

The application of TQM to the university management will contribute to building quality culture in the university's quality in which quality matters is the common responsibility of all members, all are the self-managers. So, the division of task, power, specific condition for each member to build action plan for himself with self-monitoring and supervising the implementation of the individual to detect and adjust to accomplish their assigned tasks with the motto "Do it right first". Through the application of TQM, the culture of the organization is changed, particularly in behavior, relationships, work methods and management, even the construction and development of traditional prestige of the organization. Thus, the application of TQM to the university management is not simply brought the university management a new management thinking, a new way, a new principle but a core matter of changing a university culture (shown in the standard, value systems, beliefs, relationships, tradition...).

\section{Applying TQM to University Management in Vietnam}

The application of TQM to the university management is a comprehensive solution in an effort to reform the management of higher education quality in Vietnam today. For this, universities need to implement the following comprehensive solutions:

\section{a) Building quality policy of the university}

Quality policy is a statement about the commitment of universities to ensure that the program will provide qualitative higher education programs. So, the first important thing for a university is to have a clear policy on quality. That policy must be made in the guidelines, objectives and strong strategic plans. Moreover, the quality policy of the university should be toward achieving the desired quality for the purpose of satisfying the needs of "customers". One thing to note is that the quality policy of the university being built and announced with the participation of all members of the university (administrators, lecturers, students) and the "customer" of the university (parents of students, employers, educational institutions). From this, a quality policy of the university will ensure the practicality and feasibility instead of quality policy of the university built by a few individuals or a department assigned as the current.

\section{b) Raising awareness and commitment of all members}

A organization successfully applied TQM will create a sense of pride and opportunities of development for all people and all members of the organization voluntarily committed her to the work of the highest quality. For this, through meetings or by writing, universities need to guide and exchange so that members in the university understand the concepts of quality and related concepts. Thus, they clearly aware improving education quality of university which is the responsibility of all members and they will be self-consciously, do the work with the motto "Do it right first" and "every person completes the work themselves with the highest quality". In addition, university leaders need to commit to the quality policy. This shows the quality policy of university is consistency implemented.

\section{c)Applying teamwork method replaces hierarchical organization}

Management methods in the model of management functions widely used in universities in Vietnam today are administrative and subsidy, creating barriers between members of the university and affect education quality. Applying teamwork form to implement job will create opportunities for contacting, exchanging, breaking down barriers between individuals, enhancing and making communication wholesome between individuals in the group and between groups with each other. Therefore, in the process of applying TQM to the university management, building and developing teamwork through the implementation of teams will bring high effect as well as simultaneously communicating information in universities.

- Establishing an information network widely in university

Information is the lifeblood of management. So, ensuring that two-way management information throughout, accuracy, timeliness is extremely important, especially when applying quality management in general and applying TQM in the universities in particular. Universities need to create two-way communication network seamlessly from university leaders to administrators, faculty, students, and parents of students. In addition, it helps leaders get right decisions as well as good feedback mechanisms to adjust timely decisions to solve problems in the process of implementing the action plan to create cohesion and unity in university. Besides, develop diversification of communication channels such as by writing or through the forum, the universities' site...

\section{d) Building quality culture in university}

TQM is applied comprehensively, smoothly if and only if all members of the university implementing its work voluntarily with the highest quality and all the actions of individuals are for total general quality of university. In other words, that's when quality has become a culture or cultural quality of the universities built and developed. Therefore, universities need to focus to create a healthy working environment and collaboration, learn, share experiences between colleagues aimed at improving the quality of teaching to give the learners more development opportunities. Besides it needs making an objective evaluation, fairness in order to create confidence among members in universities to promote the role and autonomy of the staff and lecturers so that they can

\section{Volume 5 Issue 5, May 2016}




\section{International Journal of Science and Research (IJSR) \\ ISSN (Online): 2319-7064}

Index Copernicus Value (2013): 6.14 | Impact Factor (2014): 5.611

contribute to the idea of building growing university.

\section{e) Implementing continuous improvement aimed towards satisfying the needs of "customer"}

TQM seeks to meet the needs of "customer" through the implementation of continuous improvement, improving gradually. Universities need to improve each step firmly, continuous improvement, to inherit the strengths and overcome weaknesses gradually. Besides universities need to improve environment of teaching and learning to ensure the health of staffs, lecturers, students as well as enhance education quality of universities towards satisfying the needs of "customers".

\section{f) Using measurement tools effectively to assess quality}

Applying TQM in management, institutions requires use effective methods of assessment such as assessment systems; assessment, organizational, factors assessment and gathering ideas for feedback to assess the quality of the daily work of the university as basis to provide comments on management effectiveness and suggest for improvements.

g)Building management processes on the basis of using PDCA cycle (Plan - Do - Check - Act)

Applying TQM requires the effective management of all stages of work. So, the university needs to build work management processes on the basis of PDCA cycle used in specifying work to be done, responsibility person, timing and implementation process helping to make clear its mission and how to conduct operations. In addition, complete the documents system which is used to be in management process to achieve quality goal.

\section{Conclusion}

TQM is a philosophy, a management system seeking to satisfy the needs of customers with the implementation of continuous improvement and building quality culture of the organization, ensuring communication and information in a widely cultural change through the group-work method. In terms of universities in Vietnam today, depending on the level of development and quality control of each unit, the university may have chosen to apply the basic characteristics of TQM and apply TQM to a fully synchronized in the future. Applying TQM in university management, universities in Vietnam themselves ensure and improve education quality and contribute to the successful implementation of management innovation of higher education according to the development strategy of education in period from 2011 to 2020 .

\section{References}

[1] Vu Song Binh, Total Quality Management, Publisher of Hanoi National University, Ha Noi, 2003.

[2] Tran Khanh Duc, Management and Accreditation Personnel Training on ISO and TQM, Publisher of Education, Ha Noi, 2005.

[3] SIMS, S.J. and R.R. SIMS, eds., Total Quality Management in Higher Education: Is It Working? Why or Why Not? London: Praegar, 1995.
[4] Strickland, Jack C, TQM: Linking People and Processes for Mission Excellence, Army Research Development \& Acquisition Bulletin, 1989.

[5] VOEHL, F. ed., Total Quality in Higher Education, Florida: St. Lucie Press, 1994

\section{Author Profile}

Nguyen Quang Giao is Vice Director of Department of Higher Education Quality Assurance, The University of Danang, Vietnam. $\mathrm{He}$ is a doctor on education management. His research areas are the management of higher education quality. He has performed seven scientific researches and more than 40 scientific papers published in the special journals of the Ministry of education - training and The Danang University in 2004 so far as: Journal of Education; Journal of science education; Journal of science - technology of Danang University. In addition, many works have been reported in the national and international science education proceedings and workshops.

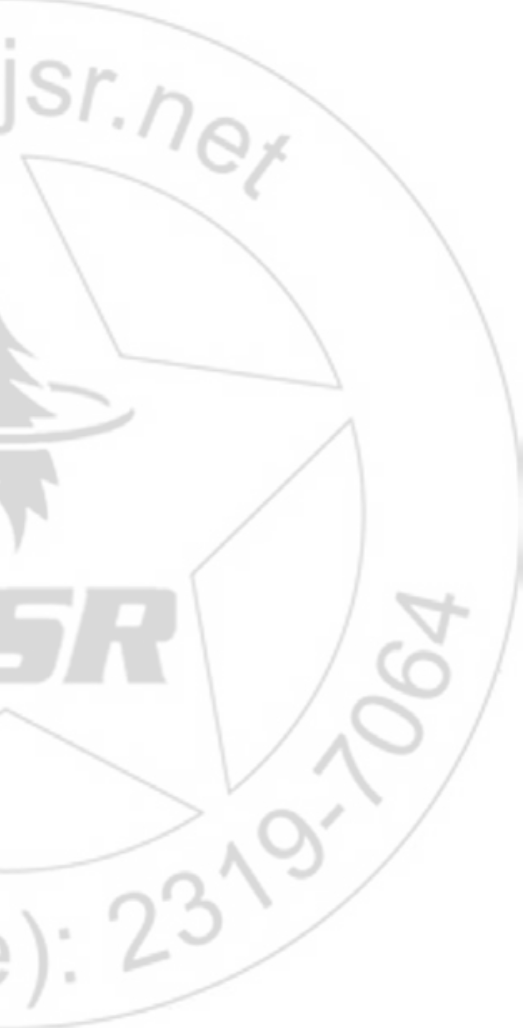

